\title{
Establishment of Effect Evaluation System for Online Teaching Mode Under the Background of "Internet plus Education"
}

\author{
Zhanxiu Cai ${ }^{1}$ \\ ${ }^{1}$ School of Life Science and Technology, Weifang Medical University, Weifang, Shandong, China 261000 \\ *Corresponding author. Email: cai.zhan.xiu@163.com
}

\begin{abstract}
The outburst of COVID-19 promoted the fast development of the online education mode of "Internet + education". However, compared with the traditional offline teaching mode, the online education mode of "Internet plus education" is not mature enough because of its short development time. Especially, there is no effective evaluation index, so it is difficult to guarantee the teaching effect. Therefore, this study proposed to explore an effective effect evaluation system by carrying out large-scale data analysis and statistics based on the large-scale online teaching during the epidemic period. Firstly, aiming at the influencing factors of "online live broadcast teaching mode" as well as the weight of each factor, then, developed the evaluation system of "online live broadcast teaching mode" by integrating all levels of universities and majors, finally, optimized and improved the established "online live broadcast teaching mode" evaluation system in comparison with traditional evaluation methods. The theory established in this mode is more objective, which is conducive to promoting the application of online teaching mode in higher education in the post epidemic era, transforming and developing the main elements of teaching subjects, teaching resources and teaching media in the "Internet plus" era, and innovating the talent cultivation mode under the information technology and improving the quality of personnel cultivation.
\end{abstract}

Keywords: Internet plus education, higher education, online teaching mode, teaching effect evaluation, talent cultivation

\section{INTRODUCTION}

"Teaching mode" is a relatively stable framework and procedure of teaching activities established under the guidance of certain teaching ideas or theories, which is characterized by orderliness and operability. In 2020, the outburst of COVID-19 made the colleges and universities in the whole country restricted by the traditional offline teaching mode. With the spirit of reform, we seized the opportunity to explore a new effective online teaching mode for higher education during the COVID-19 in order to further implement the spirit of epidemic prevention and control of the central and provincial Party committee and governments, help to win the fight in the epidemic prevention and control, adhere to the instructions of keeping learning and teaching with the class suspended [1]. It is of great significance to "keep leaning and teaching with class suspended" and ensures the quality of teaching. Recently, with the development of science and technology and the application of new technologies and results in the teaching of colleges and universities [2], teaching conditions and operation procedures from the five teaching mode factors were promoted to have an obvious change, and "contention of a hundred schools of thought and all flowers bloom together" in teaching mode. Among the numerous teaching modes, "online teaching mode" taking "Internet plus education" as new technical means is favored by more and more people due to the flexibility of teaching methods which highlight students' central position and emphasizing the cultivation of students' self-learning ability.

However, due to limited application scope of "Internet plus education" online teaching mode in the national colleges and universities, short implementation period and controversial issues about the objectivity and effectiveness of the online teaching effect evaluation, how to evaluate and guarantee the teaching effect of online teaching mode during the epidemic period is promoted to be a primary consideration [3].

If we analyzing the advantages of online network platform separately, ignoring the major specialty and cultivation objectives, this evaluation mode is lack of practicality. However, if we make the evaluation only limited to specific majors, examination results or scientific research achievements of individual excellent students, it is obviously not objective enough, and it is difficult to be universal.

Therefore, it is obviously necessary to establish an evaluation system and evaluation index based on multiple factors such as comprehensive learning situation analysis, major characteristics, network platform, cultivation 
objectives, ability cultivation and moral education requirements [4-5] to objectively evaluate the teaching effect of online teaching mode, and the index evaluation system is of significance in promoting the reform of online teaching mode and promoting the transformation and development of the "Internet plus education" teaching subjects, teaching resources and teaching media in post epidemic era.

\section{COMMON FORMS OF ONLINE TEACHING MODE}

\section{1. "Course Recording and Broadcasting Mode"}

"Online teaching mode" appeared as "course recording and broadcasting" teaching mode in the public field of vision in the early stage mainly through online schools, training institutions and so on. The "course recording and broadcasting" teaching mode adopts a basically unified mode, that is, relying on the well-known offline education entities, it can shows a better teaching effect based on careful design and post-processing by selecting excellent teachers to record learning videos and publishing them on the website for learners to learn. At present, we can still check the national excellent courses of higher education through iCourse, MOOC for college students, open.163.com and other websites. It is undeniable that the emergence of a large number of excellent network open courses and other network resources has broken the campus barriers, and the "course recording and broadcasting" teaching mode has effectively solve the problems of insufficient and unbalanced educational resources. However, some of the research results show that the teaching effect of "course recording and broadcasting" teaching mode is poor due to the lack of effective supervision and interaction in the practical teaching process.

\section{2. "Online Live Broadcast Mode"}

Due to the problems exposed in the "course recording and broadcasting" teaching mode, "online live broadcast teaching mode", another "online live teaching" mode, came into being. At present, "online live broadcast" teaching mode is mainly based on B2C mode and $\mathrm{C} 2 \mathrm{C}$ mode, among which B2C mode is represented by New Oriental Online, XRS Online School and other offline training institutions, while $\mathrm{C} 2 \mathrm{C}$ mode is usually selected by YY, Yuanfudao and other online education companies with internet background. Based on the survey results and compared with the " course recording and broadcasting", the "online live broadcast" teaching mode has better solved the problems of poor self-learning initiative, unsupervised and non-interactive teaching links in the teaching process of the "course recording and broadcasting mode" [6].
However, the practical effect of teaching interaction is often restricted by factors such as student scale, information technology, network resource platform and auxiliary facilities, etc.

Compared with the traditional teaching mode, the two online teaching modes have their own advantages and disadvantages through the above analysis, but based on the needs of online teaching mode in the epidemic and post epidemic era; "online live broadcast mode" is more applicable. Therefore, it is urgent to explore an effective effect evaluation system for the "online live broadcast mode" to ensure the quality of teaching.

\section{ESTABLISHMENT OF TEACHING EFFECT EVALUATION INDEX SYSTEM}

Considering that any kind of teaching mode should have the common attribute of serving the teaching quality, the system should consider not only the learning situation analysis, major characteristics and moral education requirements, but also the index system of teacher's evaluation for students and student's evaluation for teachers, in order to ensure the effectiveness of the "online live broadcast mode" teaching evaluation system [7]. Each index reflects the weight of specific teaching effect evaluation by scoring. It can be summarized as a "multi-directional, multi-level, multi-dimensional, interactive" teaching effect evaluation system reflecting the weight. The established evaluation system can not only be used to guide the establishment of "online teaching mode" and promote the design of "online teaching mode" to be more scientific and reasonable, but also can be used for real-time evaluation in the process of "online teaching mode", taking into account the flexibility and universality of teaching modes for different majors.

\subsection{Study Object}

Due to the limitation of "offline traditional face-to-face teaching mode" during the epidemic period, most of the undergraduate colleges and universities in China can only rely on "online live broadcast teaching mode". Therefore, we can seize the opportunity to develop and design a questionnaire to investigate the teaching situation of all kinds of major courses in the same period. The questionnaire is divided into engineering, science and liberal arts according to the nature of the courses.

\subsection{Research Methods}

\subsubsection{Index identifying of "online live broadcast teaching mode" influencing factors}

The index identifying of "online live broadcast teaching mode" influencing factors are mainly made by 
questionnaire. In order to determine the content of the questionnaire, first of all, we should systematically analyze the published literature on the theory and practice of "online teaching mode" at home and abroad, and systematically analyze the evolution of the teaching evaluation system [8] by using bibliometric and SWOT analysis, summarize and statistically analyze the relevant characteristics, and screen the preliminary indexes. Secondly, we should sample different levels of college teachers, students and managers with the same major attributes with those of online live broadcast courses in China randomly sampled to understand the actual problems in the teaching process and determine the secondary indexes. Then, for all the above indexes, industry and education experts are invited to discuss, and the important quadrant analysis [9] is used to identify the key influencing factors as the final index to evaluate the teaching effect of online live broadcast teaching mode. Finally, the above indexes are formed into the main contents of the questionnaire survey, and a large-scale survey is carried out for different majors across the country. The main purpose of the survey is to understand the rationality of index determination and weight distribution suggestions.

\subsubsection{Development of evaluation system of "online live broadcast teaching mode"}

Table 1 Evaluation system scale

\begin{tabular}{|c|c|c|c|c|c|c|c|c|c|}
\hline & \multicolumn{8}{|c|}{ Multi-level (scoring) } \\
\hline & & \multicolumn{2}{|c|}{ Engineering } & \multicolumn{2}{|c|}{ Sciences } & \multicolumn{2}{|c|}{ Liberal arts } & \multicolumn{2}{|c|}{$\ldots \ldots$} \\
\hline & & Bachelor & $\begin{array}{l}\text { Junior } \\
\text { college }\end{array}$ & Bachelor & $\begin{array}{l}\text { Junior } \\
\text { college }\end{array}$ & Bachelor & $\begin{array}{l}\text { Junior } \\
\text { college }\end{array}$ & Bachelor & Bachelor \\
\hline \multirow{6}{*}{ Multi-directional } & $\begin{array}{l}\text { Self-study } \\
\text { time }\end{array}$ & a1 & b1 & $\mathrm{c} 1$ & d1 & e1 & f1 & \multicolumn{2}{|c|}{$\ldots \ldots}$. \\
\hline & $\begin{array}{l}\text { Attendance } \\
\text { rate }\end{array}$ & a2 & b2 & $\mathrm{c} 2$ & $\mathrm{~d} 2$ & e2 & $\mathrm{f} 2$ & \multicolumn{2}{|c|}{$\ldots \ldots}$. \\
\hline & In-class test & a3 & b3 & c3 & $\mathrm{d} 3$ & e3 & f3 & \multicolumn{2}{|c|}{...... } \\
\hline & $\begin{array}{l}\text { Classroom } \\
\text { interaction }\end{array}$ & a4 & b4 & c4 & $\mathrm{d} 4$ & e4 & f4 & \multicolumn{2}{|c|}{$\ldots \ldots$} \\
\hline & $\begin{array}{l}\text { Examination } \\
\text { result }\end{array}$ & a5 & $\mathrm{b} 5$ & $\mathrm{c5}$ & $\mathrm{d} 5$ & e5 & f5 & \multicolumn{2}{|c|}{$\ldots \ldots}$. \\
\hline & $\begin{array}{l}\text { Science and } \\
\text { technology } \\
\text { project launch }\end{array}$ & a6 & b6 & c6 & d6 & e6 & f6 & \multicolumn{2}{|c|}{$\ldots \ldots}$. \\
\hline \multirow{3}{*}{ Multi-dimensional } & $\begin{array}{l}\text { Teacher's } \\
\text { evaluation for } \\
\text { students }\end{array}$ & $\mathrm{a} 7$ & b7 & c7 & $\mathrm{d} 7$ & e7 & $\mathrm{f} 7$ & \multicolumn{2}{|c|}{$7 \ldots .}$. \\
\hline & $\begin{array}{l}\text { Student's } \\
\text { evaluation for } \\
\text { teachers }\end{array}$ & $\mathrm{a} 8$ & $\mathrm{~b} 8$ & $\mathrm{c} 8$ & $\mathrm{~d} 8$ & e8 & f8 & \multicolumn{2}{|c|}{$\ldots . .}$. \\
\hline & $\begin{array}{l}\text { Evaluation of } \\
\text { the third-party }\end{array}$ & a9 & b9 & c9 & d9 & e9 & f9 & \multicolumn{2}{|c|}{$\ldots . .}$. \\
\hline
\end{tabular}

Notes: For a,b,c,d..., the specific weight is determined according to the results of the questionnaire

For the determined factors, according to the results of the survey, analytic hierarchy process, expert's advice, we will 
determine the index weight and optimal weight ratio, forming a complete "online live broadcast teaching mode" evaluation system. The index system reflects "multi-directional, multi-level and multi-dimensional" features, and also reflects interactivity. It not only covers the investigation of professional ability and accomplishment, but also reflects the evaluation of the improvement of students' moral education. The so-called multi-directional means the qualitative and quantitative point of view. The quantitative indexes include (student size, self-study time, attendance rate [10], accuracy of in-class test, classroom interaction participation, test score distribution, science and technology project launch), etc., and the qualitative indexes include (team cooperation ability, innovation ability, literature access ability, moral education promotion), etc.; The so-called multi-level means that the data collected by the questionnaire to determine the evaluation system indexes include not only ordinary colleges and universities and double first-class construction famous schools, but also medical [11], liberal arts, engineering [12] and science and other majors; The so-called multi-dimensional means that the evaluation of teaching effect not only covers the experience of teachers and students, but also the supervision and management of school administrators [13]; The so-called interaction refers to the infiltration of moral education in major education, while the cultivation of professional quality relies on the guidance of moral education, and the weight of each index reflects the interactive characteristics of its contribution to the overall effect.

\subsubsection{Practice and optimization of "online live broadcast teaching mode"}

Taking the opportunity of "online live broadcast teaching mode" application in China and based on the applicable of teaching effect evaluation index system in different majors, we can timely analyze and give feedback according to the collected big data in the application, and dynamically find problems in real time, and modify and improve them. Comparing the results of the modified and determined system with the summative evaluation system of traditional teaching mode in the same major and course, we further optimize and improve the teaching effect evaluation system to form a complete and effective system. The whole establishment process is shown in Figure 1, and the evaluation system scale is shown in Table 1.

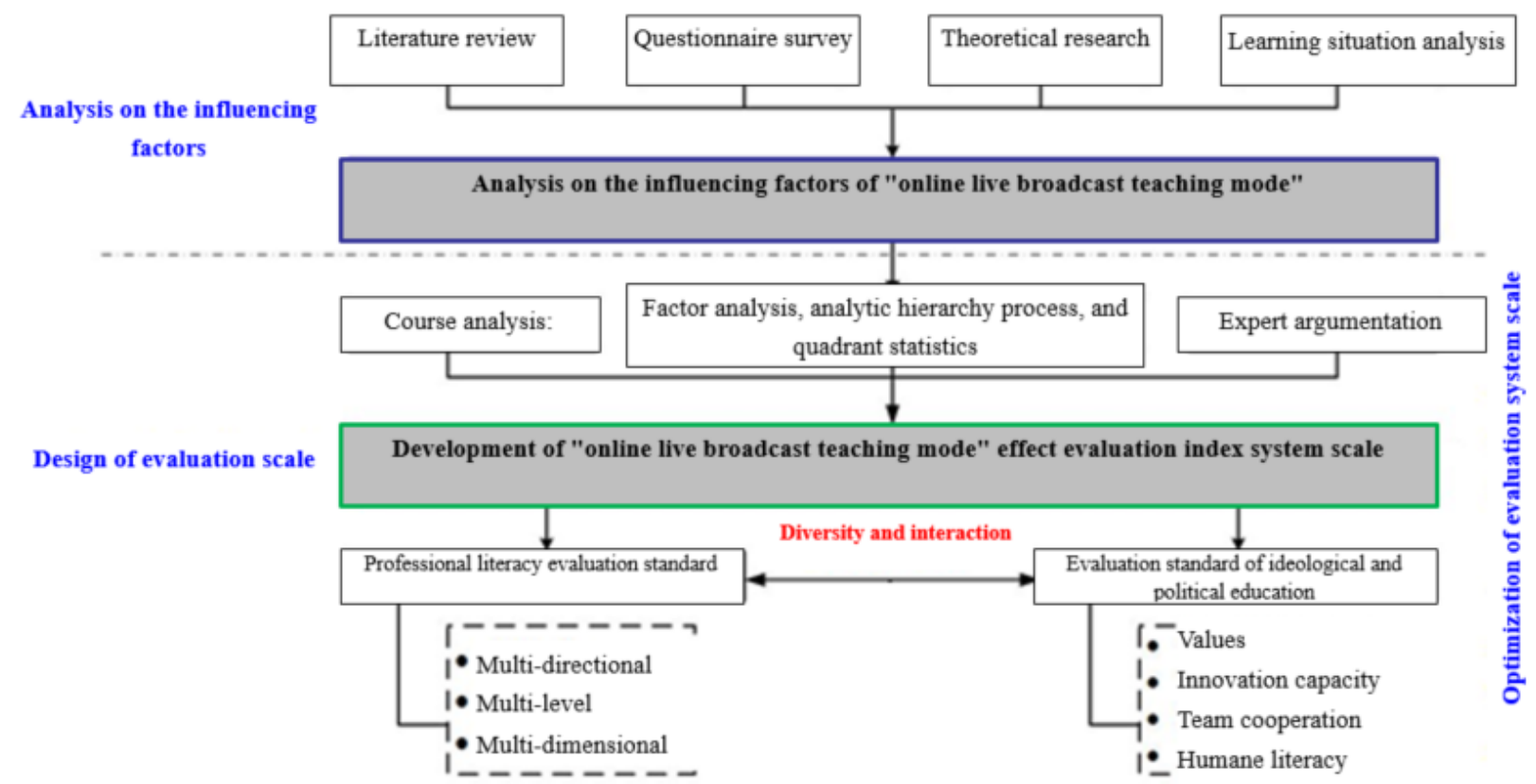

Figure 1 Evaluation design process

\section{CONCLUSION}

With the improvement of network resource coverage and the continuous development and improvement of information technology, "online teaching mode" has gradually developed into a powerful supplement to "offline traditional face-to-face teaching mode" in undergraduate teaching of higher education [14]. Online teaching mode is conducive to giving full play to the role of network resources in preview before class, ability development and quality improvement in actual teaching, improve students' interest in learning and enhance learning effect. It is also beneficial for teachers to carry out inquiry and inverted 
teaching through the network, so that teachers can change from "actors" to "directors", and give full play to students' subjective initiative to solve problems by themselves through network. However, for the "online teaching mode", if there is no effective evaluation system in the actual teaching process, it will be difficult to ensure the teaching effect and quality. We should establish a multi-directional, multi-dimensional, multi-level teaching effect evaluation system with specific evaluation indexes and values based on the common attributes that any teaching mode should serve for teaching quality assurance, such as reflecting the major characteristics, industry requirements, ideological and political education, scientific research literacy and other requirements. The evaluation index system not only applies to engineering and science, but also takes into account the multi-dimensional management of teachers and students. It not only reflects the summative evaluation, but also has the advantage of process evaluation.

\section{ACKNOWLEDGMENT}

This study was completed in Weifang Medical University supported by teaching reform and research project: Talent Cultivation Mode Exploration and Research for the Major of Biomedical Engineering under the Background of New Engineering (2018ZD003) and the "13th Five-Year Plan" of Shandong Province Teaching Science Project: Study on teaching organization mode for the Major of Biomedical Engineering in Medical Colleges and Universities Based on the Cross Integration of New Engineering and New Medicine (2020QZC020).

\section{REFERENCES}

[1] http://www.gov.cn/xinwen/2020-01/30/content_547 3048.htm

[2] Hui SU, Qiujuan MA, Baowen HU Strategies and Thoughts on Online Teaching of Major Courses in Colleges and Universities [J] Heilongjiang: Higher Educational Research and Evaluation, 2021 (01) 24-25.

[3] Ziling LUO Primary Exploration on the Digital Divide of Online Education in the Post Epidemic Era [J]. China Newspaper Industry, 2021 (02): 22-23.

[4] Yanjuan ZHENG, Gang CHEN Design and Research of Teaching Quality Evaluation Method of Colleges and Universities Based on Alliance Chain [J] Wireless Internet Technology, 2020, 17 (24): 42-44.

[5] Yueying GUO, Quan SHUANG, Chunming DING, Xingjie ZHANG Thought and Exploration of Internal
Evaluation System of Colleges Based on Audit and Evaluation [J]. Light Industry Science and Technology, 2020, 36 (12): 84-85+108.

[6] Siying MO. Thought on the Current Situation of Students' Independent Learning during the Epidemic Period [J] Modern Business Trade Industry, 2021, 42 (06): 126-127.

[7] Min ZHAO Exploration and Practice of Diversified Teaching Evaluation Modes in Colleges and universities [J] Shandong Chemical Industry, 2020, 49 (19): 222-223.

[8] Yuyang LI. Design of Teaching Quality Evaluation Model of Colleges and Universities Based on Data Mining Algorithm [J] Modern Electronics Technique, 2020, 43 (17): 119-122.

[9] Tiehua ZHOU, Wenlong LIANG, Cuifang ZHANG, Ling WANG Study on Teaching Quality Reform Measures of Colleges and Universities Based on Data Information Guarantee System [J] Wireless Internet Technology, 2020, 17 (12): 61-62.

[10] Peng LI, Shuming YI. Evaluation of the Application Effect of "Rain Classroom" in "Three-stage Study Guidance" Before, during and after Class [J] Chinese Nursing Research, 2018 (04)

[11] Jingxian JIANG, Liang LIU Evaluation, Reflection and Countermeasures of Classroom Teaching Quality in Medical Colleges and Universities [J] China Higher Medical Education, 2019 (12): 46-47.

[12] Yong LIU, Binghui YAN, Haitao XU, Dan LIU Reform of Practical Education Mode of Comprehensive Multi-skill Training for Electronic Information Major [J] Journal of Higher Education, 2020 (16): 79-81.

[13] Zhenyu JI, Yimin ZHOU, Bin YANG, Xuetao SHI, Ruigang LIU, Feng FU Teaching Design and Practice of Biomedical Major Courses under the Background of New Engineering and New Medicine [J] Medical Education Research and Practice, 2020, 28 (03): 374-376.

[14] Hui SU, Qiujuan MA, Baowen HU Strategies and Thoughts on Online Teaching of Major Courses in Colleges and Universities [J]. Heilongjiang: Higher Educational Research and Evaluation, 2021 (01): 24-25. 